\title{
A experiência do observador e a Leitura Significativa: um rio acima de todas as margens
}

\section{The experience of the observer and the Significant Reading: a river beyond all banks}

Gisélia Oliveira de Sá Neves, graduada em Letras, é mestra em Educação, pela Universidade Braz Cubas (UBC), com ênfase em Alfabetização. Professora efetiva no Ensino Fundamental I, formadora de professores alfabetizadores na Rede de Ensino da Prefeitura de Santa Isabel-SP.

Contato: eguges@gmail.com

\section{Resumo}

Este artigo objetiva discutir a Leitura Significativa segundo Frank Smith (1999), partindo das experiências do observador que representa o leitor que lança mão de suas experiências leitoras para dar sentido ao texto que lê. 0 título remete ao conto A terceira margem do rio, de Guimarães Rosa, mas as discussões não se atêm ao enredo, apenas se apoiam na ideia do rio como metáfora do ato de ler, que é margeado por vários obstáculos na busca de compreender o que está por vir. A Leitura Significativa dá sentido ao texto e ao ato de ler, que é pessoal e intransferível, embora seu resultado possa ser compartilhado com o outro. A Leitura Significativa é resultante de vários processos por que passa o leitor até se tornar um observador experiente.

Palavras-chave: leitura, Leitura Significativa, estratégias de leitura, leitor.

\section{Abstract}

This paper aims to discuss the Significant Reading according to Frank Smith (1999), based on the experiences of the observer that represents the reader who resorts to his reading experiences to give sense to the text he reads. The title refers to Guimarães Rosa's short story, The third bank 
of the river, but the discussions are not limited to the plot. They are only based on the idea of the river as a metaphor of the reading act, which is bordered by several obstacles in the search of understanding what is coming. The Significant Reading gives sense to the text and to the act of reading which is personal and untransferable, although its result can be shared with others. The Significant Reading is a result of various processes the reader goes through until he becomes an experenced reader.

Keywords: reading, Significant Reading, reading strategies, reader.

\section{Conhecendo o leito do rio}

0 título deste artigo utiliza uma metáfora que remete a um dos mais famosos contos de Guimarães Rosa, A terceira margem do rio. Um tom enigmático envolve seu enredo, quando um homem abre mão da convivência em família e parte para viver dentro de uma canoa, como solitário navegador a esmo pelas águas de um rio cheio de cumplicidades.

0 personagem-narrador, embora não fique todo o tempo observando o curso do rio, não apaga de seu pensamento o curso das águas que o afastaram de seu pai. É um observador que busca respostas, ora cheio de esperanças, ora abalado com as negativas que se seguem. "[...] mas minha irmã teve menino [...] viemos todos, no barranco, foi num dia bonito [...]. A gente chamou, esperou. Nosso pai não apareceu. Minha irmã chorou, nós todos aí choramos abraçados." (ROSA, 2001, p.83).

Entre tantas interpretações possíveis, a terceira margem do rio é um espaço aberto no infinito como um convite para a liberdade de pensar, deduzir e observar mensagens escondidas no texto. 0 mistério está no rio. Para uma Leitura Significativa, ou seja, aquela em que o leitor dá sentido ao que lê e o contextualiza segundo suas experiências e outras informações que a vida lhe oferece, é necessário ir além dos obstáculos que aparecem lado a lado do sujeito leitor.

O leitor, nesse trabalho, é a representação do aluno no processo de alfabetização nos anos iniciais de sua vida escolar.

No ato de ler, o sujeito é como um rio de águas calmas que desenha seu percurso de acordo com os percalços que lhe aparecem, margeando seus contatos com o escrito. 0 tempo 
passa e, mais experiente, esse desbravador de textos e contextos desenvolve comportamentos distintos e pessoais, de acordo com os tipos de leitura que faz.

Comparado a um rio caudaloso e de correntezas, esse mesmo leitor segue seu caminho arrastando ideias previamente formatadas, significados combinados com antecedência e, sem se deter em pré-contratos que um texto possa suportar, seleciona o que lhe convém. Elementos das duas margens que poderiam detê-lo passam a ser, no momento, o que o torna mais vivo e imponente.

Ao ler um conto, uma fábula, entre outros gêneros textuais, o leitor se vê envolvido numa relação de cumplicidade em que o texto, graças a seu explorador, ganha corpo, forma e sentido. Esse fenômeno ocorre por meio das experiências pessoais, individuais e únicas de cada sujeito, as quais se ligam às estruturas cognitivas com que opera o conhecimento.

A emergência está ligada à criatividade, que apresenta o novo e produz o conhecimento, enquanto o observador compreende o processo de cognição. 0 conhecimento que emerge resulta de uma organização de saberes que apresenta um produto novo constituído por particularidades de cada saber. 0 ato de ver depende do observador. 0 objeto observado é resultante do ato de ver. Maturana (1997) afirma que o ato de perceber constitui o percebido.

Com a experiência do observador, aproxima-se o imaginário que sustenta o texto com a situação reflexiva e experiente de aprendizagem em que esse leitor está envolvido. Não dá para separar o que está escrito num conto, por exemplo, do próprio ato de ler. 0 escrito, para imprimir sua existência, precisa ser lido e se torna inimaginável que se dê para ler (decodificar) o que não está disponível para a leitura.

Essa leitura para cada um toma uma forma porque está ligada ao que o leitor sabe ou não sobre os elementos do texto, imprimindo-se, também, o que já vivenciou da temática textual, ou mesmo ouviu dizer sobre.

Este artigo apresenta duas facetas de um leitor que não se dissociam no ato de ler, pois este é um ser observador em sua humanidade e, ao mesmo tempo, um ser criativo em seu aspecto cultural. Tais condições devem ser religadas para que a leitura se torne significativa e contribua para o processo cognitivo do homem. 


\section{Os caminhos da navegação}

0 viver de quem observa é que constitui a hibridação entre o ser e o que ele vê além dele. Embora ambos apresentem características distintas, um e outro vivem à deriva natural, ou seja, sem um destino certo, à mercê de contínuas mudanças, sem antecipação de resultados, quando ocorre um acoplamento estrutural entre o ser vivo e o que ele observa. Maturana fala de acoplamento estrutural como "uma condição de complementaridade estrutural entre o sistema e o meio no qual as interações do sistema são apenas perturbações" (1997, p. 86).

\footnotetext{
Conhecer, assim como adaptar-se, é apresentar uma conduta adequada, uma conduta congruente com a circunstância na qual essa mesma conduta se realiza, sendo ambos possibilitados e determinados pela estrutura do ser vivo em questão. (MATURANA, 1997, p. 23).
}

0 pensamento sistêmico, conforme explica Maturana, considera que um organismo opera num sistema fechado, para conservação de si mesmo, quando se autoproduz a partir de seus próprios componentes - na autopoiese.

A autopoiese, de acordo com Maturana (1997), está ligada à ideia de o organismo vivo participar da criação de si mesmo. Considera uma organização com autonomia em que seus elementos, em uma constante autorreferência, se organizam e se reorganizam para se manterem vivos. Numa autorreprodução esses elementos produzem outros iguais a si, a partir de seus próprios componentes, de forma circular e recursiva, enquanto interagem dentro do sistema. A sobrevivência de um ser vivo consiste nessa adaptação e conservação da própria vida; portanto, para que um organismo vivo resista, a autonomia, a autoprodução, a autorregulação e as interações com o meio são primordiais.

É uma forma de pensar que não despreza a razão, mas acredita que ela não é suficiente para explicar a vida em seu próprio desenvolvimento e subsistência. Ele vai além, quando ao racional une o imaginário, pelas artes e pela tradição, e, por meio de ações mentais e complementares, facilita as relações entre os conhecimentos que estão externos ao homem e outros que já o constituem - segundo Almeida e Knobbe (2003, p. 170), incentivando a coabitação do demônio da exatidão ao lado do demônio da sensibilidade.

Numa navegação de idas e vindas, seguindo as margens de um rio que ora oprimem, ora convidam para extrapolar os limites, 
pistas são deixadas pelo caminho, entre o que o leitor vivencia e o que apreende de suas experiências.

O imaginário apresenta inúmeras simbologias e é de lá que traz à tona a possibilidade de refletir e tornar inteligível a existência do fenômeno da vida na Terra, ou seja, a emergência da criatividade humana. 0 homem que cria, interpreta, modifica e propõe é um homem vivo, no sentido de existir.

De mãos dadas com o uso de metáforas, neste artigo apresento outras formas de lidar com processos da Leitura Significativa, segundo Frank Smith (1999), considerando leitor como um ser observador revestido de suas curiosidades humanas e como um ser criativo margeado por suas experiências de vida.

\section{Leitura Significativa}

Para discutir esse conteúdo, é preciso, antes, delinear alguns aspectos sobre o ato de ler. A leitura, no processo de alfabetização, tem seu início na decodificação, mas para alcançar significados deve ir além e chegar ao diálogo com diferentes sentidos que podem ser extraídos de um texto.

Ler, para algumas pessoas, é apenas decodificar, ou seja, juntar as letras para formar as sílabas e assim enxergar palavras Ler, no entanto, vai além da identificação de vocábulos escritos, pois estes, separados do contexto, não garantem o sentido do texto. Leitura Significativa consiste em ver o todo e nem sempre olhar para as partes. 0 significado do texto está nas palavras, nas entrelinhas e na experiência pessoal que o leitor desenvolve no contato com o texto.

\footnotetext{
Qualquer definição de leitura deve reconhecer a maneira seletiva como lemos todos os tipos de texto não nos esforçando mecanicamente para "extrair" toda a informação que o autor ou impressor nos fornece, mas procurando, deliberadamente, somente a informação da qual precisamos, como se procurássemos um caminho entre dois lugares em um mapa (SMITH, 1999, p. 107).
}

A Leitura Significativa dá sentido ao texto e ao ato de ler. 0 leitor lê uma variedade de gêneros textuais e para cada situação apresenta-se com um diferente propósito. Sendo assim, diante dessas escolhas, desenvolve diferentes comportamentos de leitor. É lendo que se aprende a ler. Ler é uma ação de sujeito único se comparada à vida. Ninguém poder viver pelo outro e ninguém 
pode ler "pelo" outro, porque, se assim fizer, ele estará lendo "para" o outro e este já não precisará mais ler. Logo, para ler com significados, o leitor, ainda inexperiente diante de um texto não deve ter receio de errar; ele precisa pôr em jogo tudo o que sabe sobre o que está buscando ler. Ler é uma oportunidade de aprender.

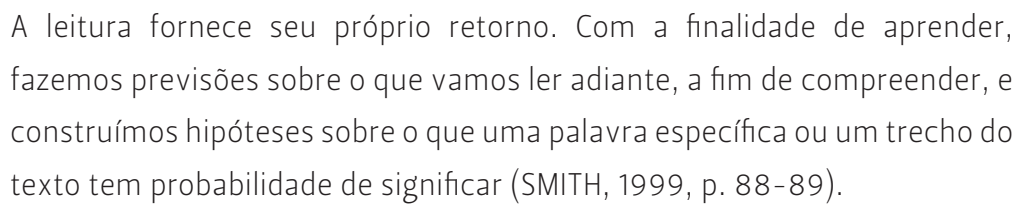

A compreensão do texto ocorre quando perguntas que se fazem ao longo da leitura - e que nascem da necessidade pessoal do leitor - podem ser respondidas por intermédio do que se apreende diante do que já está escrito. A leitura significativa não parte da busca de saber o que o autor quis dizer, mas em que ele pode contribuir nos esclarecimentos de algumas questões que emergem durante o ato de ler. "A escrita que oferece aos leitores iniciantes as melhores percepções sobre a significação da linguagem escrita geralmente está fora dos livros, no mundo mais pessoal e próximo das suas próprias vidas." (SMITH, 1999, p. 134).

Para ser um leitor mais experiente e lidar com todas as ações que encaminham a leitura de um texto, é preciso lançar mão de estratégias que são esquematizadas a partir do que se objetiva com o texto escolhido.

\section{Estratégias de leitura}

Decodificar vem primeiro na leitura; porém, quanto mais o leitor lê, menos ele olha letra por letra das palavras. "A leitura depende mais daquilo que está por trás dos olhos - da informação não visual - do que da informação visual que está diante deles." (SMITH, 1999, p.38).

As estratégias de leitura complementam a etapa da decodificação, contribuindo com ações que se encadeiam, sem a necessidade de que obedeçam a uma sequência ou mesmo que ocorram sem exceções, em todas as circunstâncias de leitura. "Uma estratégia de leitura é um amplo esquema para obter, avaliar e utilizar informação. Há estratégias de seleção, de antecipação, de inferência e de verificação." (SOLIGO, 2000, p.4).

Quando o leitor direciona o olhar para o texto em sua completude, ele vê as letras e logo seleciona o que não 
necessariamente precisa enxergar. Por exemplo, não precisa focar no 'U' que acompanha o Q, para que leia a sílaba QUE. O leitor também seleciona algumas palavras do texto que vão ao encontro do que ele quer saber, de forma que elas guiam a leitura para se chegar à informação desejada ou ao conhecimento adquirido através do texto.

As suposições do leitor diante desse mesmo texto, quando se baseiam em seus conhecimentos prévios, são resultantes de antecipações em que ele, enquanto lê o texto em sua sequência, valoriza ou descarta palavras, letras, sinais que não contribuem ou não fazem falta para que compreenda o que está lendo.

A inferência possibilita ao leitor fazer deduções sobre o texto a partir do que está escrito, mas não está dito claramente. Então, se leem as entrelinhas. Essa estratégia já supõe outra - verificação - quando o leitor busca, fazendo relações com as informações explícitas no texto, a confirmação do que ficou subentendido no encaminhamento da leitura na íntegra.

0 uso das estratégias de leitura é muito pessoal. Cada leitor, diante de um mesmo texto, utiliza-as segundo suas experiências e conhecimentos já adquiridos sobre a temática do texto. 0 leitor usa essas estratégias sem perceber que assim o faz.

Neste estudo sobre os processos de leitura, essas etapas se destacam num movimento mais lento, de forma que se perceba a sequência dessas ações complexas e coordenadas de um leitor, porque em tempo real elas chegam a ocorrer concomitantemente.

\section{As finalidades da leitura}

A diversidade de gêneros textuais contribui para as diferentes finalidades de leitura. Cada gênero textual traz imbricado um propósito de ler. "A leitura como prática social é sempre um meio, nunca um fim. Ler é resposta a um objetivo, a uma necessidade pessoal." (SOLIGO, 2000, p. 5). Para um mesmo gênero textual, dependendo das necessidades do leitor, verificam-se diferentes objetivos de leitura. Por exemplo, em uma receita de bolo, os ingredientes podem ser itens de uma lista de compras, que são lidos antes mesmo de o cozinheiro ler o texto por inteiro, e com cautela, para seguir o "modo de fazer" e chegar ao produto final, o bolo. 
informativo-científico pode ser lido para se obter uma informação global, para se buscar um dado específico ou para aprofundar um aspecto determinado do tema sobre o qual se está escrevendo [...] (LERNER, 2002, p.81).

0 que define as finalidades de leitura é a função social de um texto e o uso que se faz dele para alcançar um propósito comunicativo entre as informações que carrega e o que o leitor necessita saber.

A função social de um texto se caracteriza pelo encontro das respostas que o texto oferece com a necessidade de leitura de quem busca as informações.

O leitor experiente considera o texto a ser lido, a intenção da leitura e o uso que fará das novidades que lhe serão apresentadas pelo contexto. 0 ato de ler envolve várias finalidades, tais como: ler para estudar, ler para se informar, ler para se divertir, ler para emocionar o outro, entre outras.

\section{Comportamentos de leitor}

Parafraseando Fernando Pessoa, se navegar é preciso, ler também o é. 0 leitor experiente só desenvolve comportamentos de leitor se mergulhar de cabeça no hábito de ler.

\footnotetext{
[...] comentar ou recomendar o que se leu, compartilhar a leitura, confrontar com os outros leitores as interpretações geradas por um livro ou uma notícia, discutir sobre as intenções implícitas nas manchetes de certo jornal... Entre os mais privados, por outro lado, encontram-se comportamentos como: antecipar o que segue no texto, reler um fragmento anterior para se verificar o que se compreendeu, quando se detecta uma incongruência, saltar o que não se entende ou não interessa e avançar para compreender melhor [...] (LERNER, 2002, p.6).
}

Esses comportamentos são atitudes incorporadas à rotina de quem lê com frequência. Daniel Pennac (1993) escreveu sobre "Dez direitos inalienáveis do leitor". Entre eles, o direito de saltar páginas e o direito de reler. São marcas de atitudes autônomas em busca da leitura significativa.

Direitos imprescritíveis do leitor:

1. 0 direito de não ler.

2. 0 direito de pular páginas. 
3. O direito de não terminar um livro.

4. 0 direito de reler.

5. 0 direito de ler qualquer coisa.

6. O direito ao bovarismo (doença textualmente transmissível).

7. 0 direito de ler em qualquer lugar.

8. 0 direito de ler uma frase aqui e outra ali.

9. 0 direito de ler em voz alta.

10. 0 direito de calar. ${ }^{1}$

Dependendo da finalidade da leitura, o leitor não tem obrigação de ler um livro da capa à contracapa se a leitura não está interessante. 0 leitor pode saltar páginas ou apenas ler um ou outro trecho do livro, afirma Pennac.

Numa situação contrária a essa, há a permissão para o leitor ler o livro mais de uma vez, se assim o desejar, ou para entendê-lo mais profundamente ou para retirar dele alguns trechos que lhe serão úteis, por exemplo.

O primeiro contato com o texto ou com o livro já exige do leitor um comportamento ligado às suas experiências leitoras. Há quem escolha o livro pela capa e seus elementos (tipos de fonte, ilustrações, cores). Outros o escolhem pela quantidade de páginas, outros pela leitura do que está escrito na contracapa, ou mesmo pela admiração pelo autor.

Segundo Pennac (1993), o leitor pode escolher o comportamento de não ler. Seguindo na linha de pensamento desse trabalho, embora não haja empecilhos para a Leitura Significativa, ainda assim ela só ocorrerá se houver um pontapé inicial do leitor, ou seja, ele tem que primeiro querer ler. Querer, nessa discussão, pode abranger também sentir a necessidade de ler. Se não houver uma finalidade para a leitura, não há como ser significativa para quem lê. 0 leitor busca na leitura as respostas por que anseia, o abraço de que carece, a informação de que necessita, o conhecimento que não adquiriu, até mesmo algo que acredita poder vir a complementá-lo.

Diante de tanta liberdade de escolha de comportamentos leitores, quem lê não poder perder de vista um desses comportamentos. Para uma Leitura Significativa, ele precisa ler com fluência. Quando se detém em sílaba por sílaba, ele perde a

1. PENNAC, Daniel. Como um romance. Rio de Janeiro: Rocco, 1998, contracapa. 
visão da palavra completa e, consequentemente, o sentido global do texto. Quanto mais o leitor lê, mais conexões ele faz com o que está implícito no texto. Caso se detenha em uma ou outra palavra, corre o risco de pegar um caminho errado e não enxergar o que está no texto, quer explícito ou implicitamente.

\section{Fluência na leitura}

A Fluência Leitora é remo que se usa para navegar nas águas de uma leitura com significados. É uma viagem entre margens que não demarcam, apenas são guias para o leitor que se entrega a uma peregrinação sem rumo, fadado a qualquer sina. Para seguir nessa empreitada, também são necessárias estratégias de leitura, enquanto se desenvolvem comportamentos de leitor. Tais conteúdos serão abordados um a um na sequência deste texto, com o intuito de entender o processo que envolve a aquisição de uma leitura significativa.

Essa habilidade não diz respeito somente à velocidade com que se lê, mas também à facilidade de interpretar um texto, não importando se a leitura é silenciosa ou em voz alta, se linear ou feita de uma frase aqui e outra ali.

\footnotetext{
Fluência é a capacidade de ler um texto com precisão e rapidamente e os leitores fluentes quando fazem uma leitura silenciosa reconhecem automaticamente grupos de palavras com rapidez e facilmente chegam ao significado do que leram. Quando a leitura é feita em voz alta, soa de uma forma natural sem esforço e com expressão (ARMBRUSTER, LEHR \& OSBORN 2001, p.22).
}

A fluência na leitura é que possibilita a passagem dos olhos com rapidez pelo texto diante da escolha do que o leitor busca no texto. Também é responsável pela contextualização do que se lê, pois facilita ao leitor conectar suas ideias ao que está no texto e, por conseguinte, relacionar com suas experiências de busca, de conhecimento e de aplicação prática para a vida.

Na leitura em voz alta, a Fluência Leitora auxilia no tom natural da fala do leitor enquanto se expressa; porém, depende do público, da situação de exposição, da finalidade de leitura, das condições psicológicas e emotivas do leitor no momento da leitura. Quando um leitor lê um texto na íntegra, mas não consegue se lembrar do conteúdo do que leu, esse fato tem a ver com o que já foi apresentado anteriormente sobre a finalidade da leitura. É diferente ler para se informar e ler para informar o outro. Não é a 
mesma coisa ler para estudar ou pesquisar sobre um tema e ler esse mesmo texto para comunicar a novidade.

O leitor observador é o que não só observa o que está fora e dentro do texto, fazendo relações entre o sabido e o novo, mas também se auto-observa enquanto manipulador do texto a seu favor. A ânsia de saber já está nele, mas essa curiosidade é que o torna o criador do objeto de sua busca: o conhecimento novo, a permissão para continuar vivo.

\section{Atracando no cais: algumas considerações}

O leitor é um sujeito que observa e dá forma ao que vislumbra. Num texto, as ideias estão à espera do sopro de vida. Quem vence as correntezas do imaginário com criatividade é o leitor. Enquanto lê, dá formas, cores, cheiros, texturas às mensagens que extrai do texto. É uma ação pessoal e intransferível, embora possa ser dividida com o outro.

A leitura não se ensina; ela se desenvolve pelo ato de ler. Como o rio, ela não tem parada, só nascente. Para ela não há tempo que a limite, nem restrições para mergulhar em suas águas. Ao aprender a ler, primeiro ocorrem tentativas, só depois se consolidam as habilidades leitoras, e estas permitem ao leitor nadar nas profundezas das ideias de um livro ou de um texto.

Textos e livros são naus ou canoas, dependendo da complexidade de leitura que oferecem, em meio a um oceano de descobertas ou mesmo navegando em águas calmas de um riacho. As margens, às vezes, até se perdem de vista, tamanha a aventura de vencer corredeiras e outros obstáculos que fazem o percurso.

O leitor é um observador, no sentido de quem busca pistas além da linha do rio e as reúne segundo suas experiências para dar significado ao que lê.

A Leitura Significativa é o rio que não se intimida e, ainda que oprimido pelo terreno que o margeia, recarrega sua forças com uma chuva temporã, seguindo seu caminho mesmo sem saber aonde vai chegar. 


\section{REFERÊNCIAS}

ARMBRUSTER, B. et al. Put reading first: The research building blocks for teaching children to read. Washington, DC: U.S. Department of Education, National Institute of Child Health and Human Development, National Institute of Literacy, 2001.

KNOBBE, M.M. O antropólogo, o poeta e o pintor. In: ALMEIDA, Maria da Conceição de; KNOBBE, Margarida Maria; ALMEIDA, Ângela (Org.). Polifônicas Ideias: por uma ciência aberta.

Porto Alegre: Sulina, 2003. pp. 39-43.

LERNER, D. Ler e escrever na escola: o real, o possível e o necessário. Tradução Ernani Rosa. Porto alegre: ARTMED, 2002. 128 p.

MATURANA, H. A ontologia da realidade. Belo Horizonte: Ed. UFMG, 1997. 350 p.

PENNAC, D. Como um romance. Tradução Leny Werneck. Rio de Janeiro: Rocco, 1993. 167 p.

ROSA, J.G. Primeiras estórias. Rio de Janeiro: Nova Fronteira, 2001. 224 p.

SMITH. F. Leitura significativa. Tradução Beatriz Affonso Neves. Porto Alegre: Artmed, 1999. 168 p.

SOLIGO, R. Para ensinar a ler. In: BRASIL/MEC. Programa de Formação de Professores Alfabetizadores - PROFA. Brasília: SEF/MEC, VOL.1, M1U7T8, 2000.p. 62

Recebido em: 5/04/2016

Revisto em: 23/06/2016

Aceito em: 17/05/2016

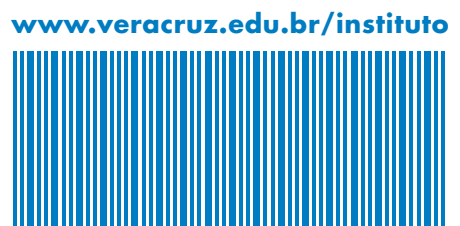

